\title{
Exploring regulatory fit between service relationships and appeals in co-production
}

\begin{tabular}{|r|l|}
\hline Journal: & Journal of Services Marketing \\
\hline Manuscript ID & JSM-06-2020-0236.R3 \\
\hline Manuscript Type: & Article \\
\hline Keywords: & Co-production, Co-creation, experimental design, Engagement \\
\hline \multicolumn{2}{|l}{} \\
\hline
\end{tabular}

SCHOLARONE $^{\text {TM }}$

Manuscripts 


\title{
Exploring Regulatory Fit between Service Relationships and Appeals in Co- Production
}

\begin{abstract}
Purpose - This paper aims to explore how different service relationships (mentoring relationship versus partnering relationship) in service co-production affect service outcomes. Specifically, it aims to explore whether the effects of service relationships on customers' intention to purchase the service are contingent upon service appeals' regulatory focus (promotion versus prevention-focused) and when the regulatory fit effects exist.
\end{abstract}

Design/methodology/approach — Three experimental studies were conducted to test the hypotheses. ANOVA and bootstrapping were used to analyze the data.

Findings - The findings of the three experiments provide convergent evidence for the hypotheses. Specifically, when customers view service employees as mentors (versus partners) in service co-production, promotion-focused (versus preventionfocus) service appeals effectively enhance customers' intention to purchase the service because customers experience a regulatory fit. Moreover, the regulatory fit effects are strengthened or attenuated according to customers' subjective social status. Research limitations/implications - Future research could use other service settings and investigate how service relationships between customers and service employees affect other important attitudinal and behavioral outcomes. 
Practical implications - Service firms could adopt promotion-focused (preventionfocused) service appeals if customers consider their relationships with service employees as mentorship (partnership), especially when customers have a higher (lower) social class.

Originality/value - To better manage service co-production, this paper investigates beneficial outcomes of mentoring and partnering relationships from a regulatory fit perspective. It highlights the importance of compatibility between service relationship and service appeals' regulatory focus and demonstrates a novel regulatory fit effect. It also uncovers engagement as the underlying mechanism for the regulatory fit effect and identifies social class as a boundary condition.

Keywords Service co-production, Service appeals' regulatory focus, Service relationships, Regulatory fit, Social class

Paper type Research paper 


\section{INTRODUCTION}

Customer co-production, which refers to "customers' participation in the creation of core offering itself' (Buettgen et al., 2012), prevails in many service industries. It takes a variety of forms in service interactions between customers and employees. Take financial counseling services as an example. Customers need to learn financial knowledge and change their usual ways to manage financial assets (Mende and van Doorn, 2015). While enjoying financial counseling services, customers may also intensively involve in service co-production, contributing a considerable amount of knowledge, information, and efforts (Buettgen et al., 2012; Dong et al., 2016).

Despite the prevalence of service co-production, research has indicated that service co-production, as a form of customer participation, may be a double-edged sword. Chan, Yim, and Lam (2010) found that although customer participation provides economical value and relational value to customers, it increases service employees' job stress and decreases their job satisfaction. Dong et al. (2015) found that the relationships between customer participation and service outcomes can be positive, insignificant, or even negative, contingent upon customer participation readiness-related factors. Therefore, researchers and practitioners have shown increasing interest in seeking effective service strategies to leverage service coproduction.

This paper addresses this issue by exploring how the relationships between customers and service employees in service co-production influence service outcomes. Based on the social relationship literature, it examines two types of service 
relationships in service co-production: partnering relationship and mentoring relationship. In a partnering relationship, service employees and customers work with each other and consider each other as equal partners (Aggarwal and McGill, 2012). Whereas in a mentoring relationship, service employees, acting as mentors, use their professional abilities to guide, train, and help customers (acting as mentees) to acquire knowledge and skills and experience personal growth and development (Snoeren et al., 2016).

By adopting a regulatory fit perspective (Aaker and Lee, 2001; Avnet and Higgins, 2006), this paper proposes that the effects of service relationships on service outcomes depend on different types of regulatory focus entailed in service appeals. Previous research shows that messages can be framed with two types of regulatory focus: promotion focus and prevention focus (Aaker and Lee, 2001; Alhouti et al., 2019; Lee and Aaker, 2004; Lee et al., 2000). In a service context, promotion-focused service appeals relate to the pursuit of gains and aspirations towards ideals, and prevention-focused service appeals relate to the avoidance of losses and the fulfillment of obligations (Lee and Aaker, 2004; Lee et al., 2000). This paper proposes that promotion-focused service appeals are more (less) effective in enhancing customer purchase intention than prevention-focused service appeals if customers view service employees as mentors (partners). These effects occur because customers experience a regulatory fit when a promotion-focused service appeal is compatible with mentoring relationship or a prevention-focused service appeal is compatible with partnering relationship (see Figure 1). 
Insert figure 1 about here

This paper makes three potential theoretical contributions. First, this paper contributes to the regulatory focus literature by proposing a new regulatory fit effect.

While partnering relationships have been investigated in the customer-brand relationship context (Aggarwal and McGill, 2012; Kim and Kramer, 2015) and mentoring relationships have been examined in the organizational behavior context (Allen et al., 2017; Haggard et al., 2011), this paper is the first to explore these two types of relationships simultaneously in service co-production. From a regulatory fit perspective, the paper explores the effect of a novel regulatory fit between service relationship and service appeals' regulatory focus on customers' intention to purchase the service and proposes engagement as the mechanism for the novel regulatory fit effect (Lee et al., 2010; Malaviya and Sternthal, 2009). Second, this paper contributes to research on regulatory fit (Avnet and Higgins, 2006; Pham and Chang, 2010) by identifying social class as a boundary condition for the regulatory fit effects in the service co-production context. Third, this paper adds to the literature on status attainment (Anderson and Kilduff, 2009; Weiss and Morrison, 2019) and social systems (Shepherd et al., 2015) by suggesting that upper-class and lower-class individuals preserve their social status in different ways. The paper's findings indicate that they are sensitive to different types of regulatory fit which can help them preserve social status in their preferred ways. 


\section{THEORETICAL BACKGROUND AND HYPOTHESES}

\section{Partnering and Mentoring Relationships in Service Co-Production}

Service relationships are likely to exist during service co-production in which customers and service employees interact with each other repeatedly (Gutek et al., 1999). Different service relationships emerge from service co-production because interactions between customers and service employees, such as sharing responsibilities and assigning tasks to co-produce the service, may differ. A mentoring relationship exists when employees work as mentors to help inexperienced customers learn knowledge and skills (Allen et al., 2017; Haggard et al., 2011). Inexperienced customers as mentees play a crucial role in transforming guidance into the knowledge and skills they want to learn. It is a common marketing practice that companies position themselves as mentors. For example, Deloitte communicates itself as a mentor to customers by stating that it is a global leader in professional services. One of the fundamental attributes of a mentoring relationship is producing developmental benefits related to mentees' work and career (Haggard et al., 2011). Knowledge, skills, and abilities demonstrated by mentors help mentees learn to adapt to their tasks (Tonidandel et al., 2007). Mentees benefit from experienced mentors' support and guidance and attain personal growth and development (Snoeren et al., 2016). For example, a gym customer plays as a mentee and learns from a fitness coach, who serves as an experienced mentor. Following the professional instructions from the coach, the customer gets healthier, both physically and mentally.

In contrast, service employees can also work as equal partners of customers (i.e., 
a partnering relationship) (Aggarwal and McGill, 2012; Huang et al., 2013; Kim and Kramer, 2015). For example, Lowe's Home Improvement claims to be a trusted partner of customers, as reflected in its advertising slogan, "Let's build something together!" Partnering relationships emphasize that service employees work with customers and coproduce benefits with customers (Aggarwal and McGill, 2012; Kim and Kramer, 2015). Both customers and employees work as equal partners to complete a task (Kim and Kramer, 2015). Customers shoulder equal responsibilities for producing the service, and their contributions to the service are as important as the contributions from employees. In the above example, the fitness coach can be an equal partner of the customer. Contributions from both the customer and the coach are equally important for the customer's better health condition.

\section{Relationship Type, Regulatory Focus, and Regulatory Fit}

This paper proposes that regulatory fit occurs when service appeals' regulatory focus matches a particular service relationship (mentoring relationship or partnering relationship) in service co-production. This proposition is twofold. On the one hand, we argue that promotion-focused service appeals work better in a mentoring relationship than prevention-focused service appeals. Previous research on mentorship has shown that mentees are receptive to mentors' career support and tend to pursue career-related gains and aspirations towards career-related ideals (Chen et al., 2017; Wu et al., 2019; Zhou et al., 2019). First, mentors can serve as role models for mentees. They convey behaviors, values, and attitudes to mentees (Zhou et al., 2019), facilitate mentees' learning of expertise such as new knowledge and perspectives, and 
help mentees develop useful personal skills such as communication and interaction skills (Kwan et al., 2010). Second, support from mentors motivates mentees to develop crucial capabilities to achieve career-related goals. For instance, mentors' support can motivate mentees to adopt proactive behaviors such as improving current circumstances, creating new circumstances, and challenging the status quo (Wu et al., 2019). These proactive behaviors have been proven to increase task engagement and performance (Bakker et al., 2012). Third, mentors' support also makes essential task resources accessible to mentees and helps them achieve career-related goals (Chen et al., 2017).

Similarly, if customers in service co-production hold a mentorship view on their relationship with service employees, they tend to pursue gains and aspirations towards ideals (Wu et al., 2019; Zhou et al., 2019). A promotion-focused service appeal matches this type of service relationship because it manifests benefits that represent achievements and ideals such as keeping healthy and energetic after gym exercise (Lee and Aaker, 2004; Lee et al., 2000). Consequently, customers are more likely to respond to promotion-focused appeals (Aaker and Lee, 2001), such as demonstrating a higher intention to purchase the service.

On the other hand, we argue that a prevention-focused service appeal works better in a partnering relationship than a promotion-focused service appeal does. Extant literature has documented that people in a partnering relationship emphasize equality between partners and avoid losses and negative outcomes (Briley and Wyer, 2002; Huang et al., 2013). For example, one study shows that when consumers 
consider the service brand as equal partners like friends, they prefer a horizontal and close brand position rather than a vertical and far brand position in the advertisement (Huang et al., 2013). When working together as equal members in a group, people are more concerned about their responsibilities and duties to their group members (Briley and Wyer, 2002). This concern will evoke people's alertness to the possible negative outcomes of a decision because negative consequences have a more significant influence on group members than positive consequences (Briley and Wyer, 2002).

Therefore, if customers in service co-production hold a partnership view on their relationship with service employees, they tend to avoid losses and adverse outcomes (Briley and Wyer, 2002; Huang et al., 2013). A prevention-focused service appeal matches the partnering relationship because it emphasizes avoidance of losses and adverse outcomes, such as avoiding obesity and sub-optimal health after gym exercise (Alhouti et al., 2019). Consequently, there should be a regulatory fit between prevention-focused appeals and partnering relationships. Consistent with prior research, this paper predicts that the regulatory fit will lead to a higher intention to purchase the service (Avnet and Higgins, 2006; Pham and Chang, 2010).

H1: When service appeals' regulatory focus is compatible with service relationship, customers will have a higher intention to purchase the service. More specifically,

H1a: Promotion-focused (versus prevention-focused) service appeals will lead to a higher intention to purchase the service when customers perceive their relationship with service employees as mentorship in service co-production. 
$\boldsymbol{H 1 b}$ : Prevention-focused (versus promotion-focused) service appeals will lead to a higher intention to purchase the service when customers perceive their relationship with service employees as partnership in service co-production.

\section{Regulatory Fit and Engagement}

Prior studies have demonstrated that engagement mediates the effect of regulatory fit on individuals' evaluative reactions (Avnet and Higgins, 2006; Lee et al., 2010; Malaviya and Sternthal, 2009). Regulatory fit increases engagement in reactions and makes individuals "feel right about their reactions" (Lee et al., 2010). The feeling-right experience will be transferred to the target being evaluated (Malaviya and Sternthal, 2009). In other words, individuals will feel right about their evaluative reactions to the target, no matter whether the evaluation is positive or negative (Cesario et al., 2004). As a result, evaluative reactions to the target will be intensified. For instance, if customers intend to purchase a service, their purchase intention will be far more higher when they experience a regulatory fit (versus a regulatory non-fit). Thus, customers who experience a regulatory fit between service appeals' regulatory focus and the service relationship should experience increased engagement in evaluating the service, intensify their evaluation for the service, and have a higher intention to purchase the service.

H2: Engagement mediates the effect of regulatory fit between service appeals' regulatory focus and service relationship on customers' intention to purchase the service.

\section{Social Class as a Moderator}


Social class refers to both individuals' objective possession of material wealth and access to resources and their subjective perception of their socioeconomic status relative to others (Kraus et al., 2012). Due to the functions that the hierarchy of social status provides, individuals tend to reinforce the hierarchy or preserve their social status (Amaral and Loken, 2016; Magee and Galinsky, 2008). For instance, system justification theory has demonstrated that no matter individuals have high or low system confidence, they have favorable evaluation for brands that they endorse as part of their social systems (Shepherd et al., 2015).

Prior research suggests that upper-class and lower-class individuals preserve their social status differently (Amaral and Loken, 2016; Kraus et al., 2012). Upper-class individuals invest more in preserving their status than lower-class individuals, given benefits like resources and power related to high social status (Amaral and Loken, 2016). We argue that upper-class individuals are more likely to view competence as a way to preserve their social status and meet high-performance expectations (Magee and Galinsky, 2008). High social status is associated with high perceived competence and drives high-performance expectations (Magee and Galinsky, 2008). Perceived competence also enhances one's social status (Anderson and Kilduff, 2009; Weiss and Morrison, 2019). Therefore, upper-class individuals tend to view competence as a means to preserve social status.

In contrast, we argue that lower-class individuals, who have limited wealth, fewer resources, and lower rank, prefer avoiding losses and negative outcomes and consider equality as a means to preserve social status (Kraus et al., 2012; Shepherd et al., 
2015). First, as lower-class individuals are frequently facing constrained external environments, they are prone to detect negative outcomes, such as threats, in the environments (Kraus et al., 2012). Furthermore, they are more likely to perceive negative outcomes even in ambiguous social situations (Chen and Matthews, 2001) and exhibit hostile reactions to ambiguous social scenarios (Kraus et al., 2011). Second, vulnerable lower-class individuals have a greater commitment to egalitarian values and are more likely to respond to threatening social environments by building social connections with others and engaging in prosocial behaviors (Piff et al., 2010). Similarly, individuals with low system confidence emphasize universalism values like equality (Shepherd et al., 2015).

In the context of service co-production, we posit that upper-class individuals will experience a stronger regulatory fit between promotion-focused appeals and mentoring relationships. The promotion focus-mentoring relationship fit not only conveys benefits such as achievements and ideals to customers (Lee and Aaker, 2004; Lee et al., 2000), but also allowed customers as mentees to get adequate support to build competence in terms of skills and abilities and obtain achievements and ideals (Tonidandel et al., 2007). We expect that upper-class individuals will consider this type of fit helpful for them to preserve their social status through building competence; as a result, they will experience a greater regulatory fit and have a higher purchase intention. When partnering relationships are perceived, upper-class individuals who look for help to build competence rather than avoiding losses and negative outcomes (Magee and Galinsky, 2008) will not find partnering relationships 
appealing and will not experience relevant regulatory fit.

In contrast, lower-class individuals will experience a stronger regulatory fit between prevention-focused appeals and partnering relationships. The prevention appeal-partnering relationship fit not only conveys benefits such as avoiding losses and negative outcomes to customers (Lee and Aaker, 2004; Lee et al., 2000), but also makes customers perceive equality and be more alert to negative outcomes (Briley and Wyer, 2002). We expect that lower-class individuals who tend to preserve their social status by avoiding losses and negative outcomes and emphasizing equality (Kraus et al., 2012; Shepherd et al., 2015) will feel more right about this regulatory fit and thus have a higher purchase intention. When mentoring relationships are perceived, lower-class individuals who emphasize equality and expect equal rather than hierarchical relationships with service employees (Shepherd et al., 2015) will not find mentoring relationships appealing and will lower their purchase intention, regardless of prevention or promotion-focused service appeals.

H3: Social class moderates the effect of regulatory fit between service appeals' regulatory focus and service relationship on customers' intention to purchase the service. More specifically,

H3a: Upper-class customers have a higher intention to purchase the service in the promotion focus-mentoring relationship fit condition than in other conditions.

$\boldsymbol{H 3} \boldsymbol{b}$ : Lower-class customers have a higher intention to purchase the service in the prevention focus-partnering relationship fit condition than in other conditions. 


\section{OVERVIEW OF THE EXPERIMENTS}

We examined the proposed hypotheses in three experiments. Experiment 1 tested the effect of regulatory fit between service appeals' regulatory focus and service relationship on customers' purchase intention in a fitness service setting. Experiment 2 replicated the findings of Experiment 1 in a car-driving training service scenario and examined the mediating role of engagement. Experiment 3 tests the moderating role of social class in the proposed regulatory fit effects.

\section{EXPERIMENT 1}

\section{Method}

Participants and design. We employed a 2 (service appeals' regulatory focus: promotion focus versus prevention focus) $\times 2$ (service relationship: mentoring relationship versus partnering relationship) between-subjects design. A total of 152 college students $\left(M_{\mathrm{age}}=21.19, S D=2.24,57.9 \%\right.$ female $)$ participated in the experiment. Participants were randomly assigned to one of the four conditions.

Procedure and manipulations. All participants read the same scenario as follows: "You are not satisfied with your body shape and often get annoyed. So you decide to take a fitness class. You receive an advertisement for a gym named Heat Gym." Then participants were exposed to different versions of advertising slogans of Heat Gym, which were used to manipulate the service appeals' regulatory focus (Aaker and Lee, 2001). About half of the participants were exposed to advertisement slogans emphasizing promotion-focused benefits of working out in the gym, such as getting healthy and energetic and being more attractive. The rest of the participants 
were exposed to advertisement slogans emphasizing prevention-focused benefits of working out in the gym, such as avoiding sub-optimal health and losing weight.

All participants were then directed to customer comments about Heat Gym, which were used to manipulate different service relationships. In the mentoring relationship condition, participants read customer comments emphasizing that fitness trainers worked as mentors to guide customers in bodybuilding. Participants in the partnering relationship condition read comments emphasizing that fitness trainers and customers worked as equal partners in bodybuilding.

Next, participants were instructed to indicate their intention to purchase the gym service on a seven-point Likert scale $(1=$ strongly disagree, $7=$ strongly agree $)$ (Poushneh and Vasquez-Parraga, 2017). The scale consisted of four items: "I will choose Heat Gym," "I think that Heat Gym will be a good choice," "I have high intention to join fitness classes in Heat Gym," and "I have high intention to purchase fitness classes in Heat Gym” (Cronbach's $\alpha=.94)$.

Participants were then asked to answer manipulation check questions for service relationships. Participants rated on four seven-point Likert items about their views towards the relationship between the Heat Gym customers and the instructors. The items were "Comments from online customers make me feel that in Heat Gym (1) customers and gym instructors have distinct roles and responsibilities; (2) customers strive for learning, and gym instructors strive for guiding; (3) customers and gym instructors are considered as equal partners to each other; (4) all members have shared tasks and responsibilities' $(1=$ strongly disagree, $7=$ strongly agree $)$. The first two 
items (Cronbach's $\alpha=.80$ ) were used to check the success of the mentoring relationship's manipulation. The last two items (Cronbach's $\alpha=.90)$ were used to check the success of the partnering relationship's manipulation. In the end, participants provided information about their prior experience of using a gym service, their workout schedule, and demographics.

\section{Results}

Manipulation checks. As expected, participants in the mentoring relationship condition rated higher on the mentoring relationship scale than those in the partnering relationship condition $\left(M_{\text {mentor }}=4.26, S D=1.53, M_{\text {partner }}=3.51, S D=1.44, t(150)=\right.$ $3.11, d=.50, p<.01)$, whereas participants in the partnering relationship condition rated higher on the partnering relationship scale than those in the mentoring relationship condition $\left(M_{\text {partner }}=4.90, S D=1.57, M_{\text {mentor }}=3.78, S D=1.47, t(150)=\right.$ $4.53, d=.74, p<.001)$. These results indicated that the manipulations of mentoring and partnering relationships were successful.

Hypothesis testing. Analysis of variance (ANOVA) showed that neither the main effect of service appeals' regulatory focus $(F=.08, n s)$ nor the main effect of service relationship $(F=.00, n s)$ on purchase intention was significant. As predicted, the coefficient of the interaction between regulatory focus and service relationship was significant $(F(1,148)=10.94, p<.01)$. These findings indicated that customers had a higher intention to purchase the gym service when they experienced a regulatory fit than when they did not. Follow-up contrast tests indicated that when the customerinstructor relationship was perceived as mentoring relationship, participants who were 
exposed to promotion-focused appeals had a higher purchase intention than those who were exposed to prevention-focused appeals $\left(M_{\mathrm{pro}}=4.22, S D=.21, M_{\mathrm{pre}}=3.47, S D\right.$ $=.23, F(1,148)=5.93, d=.50, p<.05)$; when the customer-instructor relationship was perceived as partnering relationship, participants who were exposed to prevention-focused appeals had a higher purchase intention than those who were exposed to promotion-focused appeals $\left(M_{\mathrm{pre}}=4.29, S D=.21, M_{\mathrm{pro}}=3.54, S D=.26\right.$, $F(1,148)=5.09, d=.63, p<.05)$. These results supported $\mathrm{H} 1 \mathrm{a}$ and $\mathrm{H} 1 \mathrm{~b}$, respectively (see Figure 2).

Insert figure 2 here

\section{Discussion}

The results of Experiment 1 support Hypothesis 1 that the regulatory fit between service appeals' regulatory focus and service relationship increases customers' intention to purchase the service. The experiment offers preliminary evidence for a new regulatory-fit source in the service co-production context, contributing new insights to literature on regulatory focus and regulatory fit (Lee and Aaker, 2004; Lee et al., 2000). Besides, the findings are consistent with prior research, which demonstrates the positive effect of regulatory fit on individuals' evaluative reactions (Avnet and Higgins, 2006). However, the mechanism underlying the regulatory fit effects has not been investigated in the experiment. Experiment 2 will address this issue. 


\section{EXPERIMENT 2}

\section{Purposes}

Experiment 2 has two purposes: (1) replicate and generalize the findings from Experiment 1 by testing the hypotheses in another service setting: car-driving training; (2) investigate the mechanism underlying the regulatory fit effects found in Experiment 1.

\section{Method}

Participants and design. Experiment 2 adopted a 2 (service appeals' regulatoryfocus: promotion focus versus prevention focus) $\times 2$ (service relationship: mentoring relationship versus partnering relationship) between-subjects design. A total of 133 college students in China $\left(M_{\text {age }}=20.78, S D=1.81,59.5 \%\right.$ female $)$ participated in the experiment. Participants were randomly assigned to one of the four conditions.

Procedure and manipulations. The experiment followed a similar procedure as Experiment 1. All participants read related information about XINDA, a fictitious driving school. They were exposed to the manipulation materials for service appeals' regulatory focus and service relationship according to the different conditions they were assigned to.

Service appeals' regulatory focus was manipulated through different versions of a XINDA advertisement. About half of the participants were exposed to a version of the XINDA advertisement emphasizing promotion-focused benefits of taking the school's car-driving courses, such as improving driving skills significantly and getting driving 
licenses quickly. The rest of the participants were exposed to another version of the advertisement emphasizing prevention-focused benefits of taking car-driving courses in the school, such as avoiding failing driving tests and minimizing learners' stress.

Service relationship was manipulated by driving learners' comments about the relationship between the learners and their driving instructors of XINDA school. About half of the participants read learners' comments that described themselves as mentees and their instructors as mentors in the driving courses. The rest of the participants read learners' comments depicting that instructors and learners acted as equal partners.

Next, participants were asked to rate their intention to purchase the service and perception of engagement in processing the information, answer manipulation check questions, and provide demographic information. The scale for purchase intention was similar to those used in Experiment 1. Measurement items for engagement in processing information were adapted from Lee et al. (2010). Those items were "To what extent did you feel motivated/feel right/feel wrong when you were reading the information?" ( $1=$ not at all; $7=\mathrm{a}$ lot; $\alpha=.75)$ (Cronbach's $\alpha=.75)$. To do manipulation checks for service relationship, participants were asked to indicate their opinions on the relationship between driving instructors and learners using two sevenpoint bipolar items $(1=$ mentors and learners, $7=$ partner; $1=$ more emphasis on distinct role responsibilities, $7=$ more emphasis on equal partnership; Cronbach's $\alpha$ $=.83)$.

\section{Results}


Manipulation checks. As expected, participants in the mentoring relationship condition perceived greater mentoring and those in the partnering relationship conditions perceived greater partnership $\left(M_{\text {mentor }}=3.45, S D=1.85, M_{\text {partner }}=4.24, S D\right.$ $=1.45, t(131)=2.72, d=.48, p<.01)$. In addition, participants in different relationship conditions did not differ in their rating of XINDA's training experience $(t$ $=.10, n s)$, competence $(t=.03, n s)$ and sincerity $(t=.93, n s)$. These findings confirm the success of the manipulations in the experiment.

Hypothesis testing. ANOVA analysis showed that neither the main effect of service appeals' regulatory focus $(F=.00, n s)$ nor the main effect of service relationship $(F=.56, n s)$ on purchase intention was significant. As predicted, the coefficient of the interaction between regulatory focus and service relationship was significant $(F(1,129)=12.77, p<.001)$. These findings indicated that customers had a higher intention to purchase the driving training service when they experienced a regulatory fit than when they did not. As demonstrated in Figure 3, follow-up contrast tests indicated that under the mentoring relationship condition, customers who were exposed to promotion-focused appeals in advertisement had a higher purchase intention than those who were exposed to prevention-focused appeals $\left(M_{\mathrm{pro}}=4.25, S D\right.$ $\left.=.19, M_{\text {pre }}=3.52, S D=.21, F(1,129)=6.48, d=.64, p<.05\right)$; under the partnering relationship condition, participants who were exposed to prevention-focused appeals had a higher purchase intention than those who were exposed to promotion-focused appeals $\left(M_{\text {pre }}=4.42, S D=.22, M_{\text {pro }}=3.67, S D=.21, F(1,129)=6.30, d=.62, p\right.$ $<.05)$. The results replicated the findings in Experiment 1. 


\section{Insert figure 3 about here}

A series of linear regressions were conducted to test the mediating role that engagement in processing information played in the regulatory fit effects. The results indicated that (a) the interaction between service appeals' regulatory focus and service relationship led to higher engagement $(\beta=.25, t(122)=2.37, p<.05)$, (b) engagement led to higher purchase intention $(\beta=.49, t(124)=5.83, p<.001)$, (c) the interaction had a direct effect on purchase intention $(\beta=.30, t(122)=2.71, p<.01)$ and (d) the effect of the interaction on purchase intention became insignificant $(t(121)$ $=1.81, n s)$ when engagement was included as a predictor for purchase intention, whereas the effect of engagement on purchase intention remained significant $(\beta=.45$, $t(121)=5.33, p<.001)$. Moreover, bootstrapping analysis showed that the indirect effect of service appeals' regulatory focus on purchase intention via engagement was significant for both mentoring relationships (95\% CI: [-.59, -..01]) and partnering relationships (95\% CI: $[.05, .69])$. The regression analyses and the bootstrapping analysis (Table 1 and Figure 4) provide converging evidence that the effects of regulatory fit on purchase intention were mediated by engagement. These results supported Hypothesis 2.

Insert table 1 about here 


\section{Discussion}

Experiment 2 replicates the findings of Experiment 1 and supports the mediating role of engagement (Hypothesis 2). The findings are consistent with prior research that showed the mediation role of engagement in the relationship between regulatory fit and individuals' evaluative reactions (Avnet and Higgins, 2006; Lee et al., 2010; Malaviya and Sternthal, 2009).

\section{EXPERIMENT 3}

\section{Purposes}

The purposes of Experiment 3 are to generalize the findings from Experiment 1 and Experiment 2 and investigate the boundary condition for the regulatory fit effects. The experiment also used a new approach to manipulate service relationship.

\section{Method}

Participants and design. The experiment employed a 2 (social class: high versus low) $\times 2$ (service appeals' regulatory focus: promotion focus versus prevention focus) $\times 2$ (service relationship: mentoring relationship versus partnering relationship) between-subjects design. Three hundred eighty-six participants $\left(M_{\mathrm{age}}=32.1, S D=\right.$ $6.74,54.7 \%$ female) were recruited from an online survey website and were randomly assigned to one of the eight experimental conditions.

Pilot study. A pilot study was conducted to develop a new approach to manipulate service relationship. STARFISH, a fictitious Music Training School, was 
used as the service context. Forty-five participants $\left(M_{\mathrm{age}}=31.1, S D=8.12,67 \%\right.$

female) were recruited from an online survey website and were randomly assigned to either the mentoring relationship condition or the partnering relationship condition.

Participants in the mentoring relationship condition read the following advertising slogan: "STARFISH. Guide you to experience charming music all the way. Let professional coaches guide your learning." In contrast, those in the partnering relationship condition read the following slogan: "STARFISH. Accompany you to experience charming music all the way. Let lovely coach partners accompany your learning." After reading the slogans, participants were asked to write down their thoughts about how they hoped their professional coaches/coach partners to guide their learning.

Participants were then asked to answer manipulation check questions on 7-point Likert scales for mentoring relationship and partnering relationship. The items for checking mentoring relationship manipulation were "In STARFISH, coaches and learners are more like mentors and mentees than partners" and "STARFISH attaches more importance on coaches' professional skills in guiding learners" (Cronbach's $\alpha$ $=.84$ ). The items for checking partnering relationship manipulation were "In STARFISH, coaches and learners are more like partners than mentors and mentees" and "STARFISH attaches more importance on coaches' partnership of accompanying learners" (Cronbach's $\alpha=.91)$.

As expected, whereas participants in the mentoring relationship condition rated higher on the mentoring relationship scale than those in the partnering relationship 
condition $\left(M_{\text {mentor }}=5.50, S D=1.17, M_{\text {partner }}=3.89, S D=1.53, t(43)=4.19, d=1.21\right.$, $p<.001$ ), participants in the partnering relationship condition rated higher on the partnering relationship scale than those in the mentoring relationship condition $\left(M_{\text {partner }}=5.23, S D=1.36, M_{\text {mentor }}=4.13, S D=1.52, t(43)=2.55, d=.78, p<.05\right)$.

Procedure. Participants were told to complete two unrelated tasks. The first task was used to manipulate the participants' social class perception. Following Piff et al. (2010), participants in the low (high) social class condition were asked to compare themselves with people in the highest (lowest) level of socioeconomic status in terms of income, education, and job. They were then asked to indicate the perception of their social positions in a ladder with ten rungs $(1=$ the lowest level; $10=$ the highest level).

In the second task, all participants were asked to read information about STARFISH music training school. They were exposed to manipulation materials for service appeals' regulatory focus, using the same manipulation method as Experiment 1 and Experiment 2. Next, they were exposed to the manipulation materials for service relationship developed from the pilot study. Then participants responded to the purchase intention scale (Cronbach's $\alpha=.92)$ used in Experiment 1 and Experiment 2, reported the extent to which they were interested in learning how to play a musical instrument $(1=$ not interested at all, $7=$ extremely interested $)$, and provided demographic information.

\section{Results}

Manipulation checks. Participants in the low social class condition reported 
significantly lower social status than those in the high social class condition $\left(M_{\text {low }}=\right.$ $\left.5.11, S D=1.56, M_{\mathrm{high}}=5.75, S D=1.51, t(384)=4.16, d=.42, p<.001\right)$.

Hypothesis testing. ANOVA analyses showed that service appeals' regulatoryfocus and service relationship interacted to affect customer purchase intention $(F(1$, $378)=9.63, p<.01)$. Specifically, in the partnering relationship condition, participants exposed to prevention-focused service appeals had a higher purchase intention than those exposed to promotion-focused service appeals $\left(M_{\mathrm{pre}}=5.43, S D\right.$ $\left.=.10, M_{\text {pro }}=5.05, S D=.10, F(1,378)=7.08, d=.36, p<.01\right)$. In contrast, in the mentoring relationship condition, participants exposed to promotion-focused appeals had a higher purchase intention than those exposed to prevention-focused appeals, although the effect was marginally significant $\left(M_{\text {pro }}=5.26, S D=.11, M_{\text {pre }}=5.01, S D\right.$ $=.10, F(1,378)=2.97, d=.25, p<.09)$.

More importantly, a significant three-way interaction $(F(1,378)=3.81, p=.05)$ was detected. Consistent with Hypothesis 3a, among participants with relative high perceived social status, promotion-focused service appeals were more effective in enhancing purchase intention than prevention-focused service appeals $\left(M_{\text {pro }}=5.73\right.$, $\left.S D=.15, M_{\text {pre }}=5.01, S D=.14, F(1,378)=13.14, d=1.07, p<.001\right)$ when the participants held a mentoring relationship view; whereas these two types of service appeals did not differ significantly in enhancing purchase intention $\left(M_{\text {pro }}=4.90, S D\right.$ $\left.=.15, M_{\text {pre }}=5.20, S D=.14, F(1,378)=2.22, n s\right)$ when the participants held a partnering relationship view (see Figure 5).

Besides, consistent with Hypothesis 3b, among participants with relative low 
perceived social status, prevention-focused service appeals were more effective in enhancing purchase intention than promotion-focused service appeals $\left(M_{\mathrm{pre}}=5.66\right.$, $\left.S D=.15, M_{\text {pro }}=5.19, S D=.14, F(1,378)=5.17, d=.49, p<.05\right)$ when the participants held a partnering relationship view; whereas these two types of service appeals did not differ significantly in enhancing purchase intention $\left(M_{\mathrm{pro}}=4.79, S D\right.$ $\left.=.15, M_{\text {pre }}=5.02, S D=.14, F(1,378)=1.27, n s\right)$ when the participants held a mentoring relationship view (see Figure 5).

Insert figure 5 about here

\section{Discussion}

Experiment 3 provides support for Hypothesis 3 that social class moderates the effect of regulatory fit between service appeals' regulatory focus and service relationship on customers' intention to purchase the service. Complementing prior research that primarily shows the positive implications of the regulatory fit effect (Avnet and Higgins, 2006; Pham and Chang, 2010), this study further delineates when the positive regulatory fit effect will be strengthened or weakened. The findings in Experiment 3 offer further evidence for the new regulatory fit effect in the context of service co-production.

\section{GENERAL DISCUSSION}

This paper proposes and investigates a new source of regulatory fit between 
service relationship and service appeals' regulatory focus. The empirical studies test the focal hypotheses that customers perceiving a mentoring (versus partnering) relationship with service employees in service co-production have a higher intention to purchase the service when they are exposed to promotion-focused (versus prevention-focused) service appeals. Three experiments provide convergent evidence for the proposed hypotheses in various service settings, including gym service, cardriving service, and musical training service. The findings demonstrate that engagement mediates the effect of regulatory fit on purchase intention (Lee et al., 2010). Besides, social class plays a moderating role in the regulatory fit effects.

\section{Theoretical contribution}

This research offers several contributions to extant research. First, this paper contributes to the literature on regulatory focus and regulatory fit by demonstrating a new source of regulatory fit that occurs when service appeals' regulatory focus is compatible with service relationship in service co-production. Drawing on the literature of partnering relationships examined in the customer-brand relationship research (Aggarwal and McGill, 2012; Kim and Kramer, 2015), the literature of mentoring relationships widely investigated in the organizational behavior research (Allen et al., 2017; Haggard et al., 2011), and the literature of regulatory focus (Avnet and Higgins, 2006), this paper uncovers a novel regulatory fit between service relationship and sevice appeals' regulatory focus and its positive effect on customers' intention to purchase the service. Prior studies have demonstrated the importance of regulatory fit in determining the monetary value of a product (Avnet and Higgins, 
2006), the value of group power (Sassenberg et al., 2007), or the persuasiveness of a message (Lee and Aaker, 2004). The regulatory fit effects found in the paper demonstrate another source of regulatory fit in the service co-production context. The findings of the regulatory fit effects also add to the existing literature that has explored the regulatory fit between regulatory focus and group power (Sassenberg et al., 2007), information loss and gain frames (Lee and Aaker, 2004), and message construal levels (Lee et al., 2010). Besides, this study replicates prior research by demonstrating engagement as a psychological mechanism for the regulatory fit effects (Lee et al., 2010; Malaviya and Sternthal, 2009).

Second, complementing prior research that focuses on the positive implications of various sources of regulatory fit (Avnet and Higgins, 2006; Pham and Chang, 2010), this paper identifies social class as a moderator for the relationship between regulatory fit and purchase intention. Specifically, it demonstrates that the positive implications of regulatory fit taper off if the service relationship in service co-production is not aligned with customers' social class. Findings from this study also hint the need to explore more fundamental determinants of regulatory fit in service co-production and explore various types of regulatory fit simultaneously.

Third, this paper adds to the theory of status attainment (Anderson and Kilduff, 2009; Weiss and Morrison, 2019) and literature on social systems (Shepherd et al., 2015) by pinpointing that both upper-class and lower-class individuals are motivated to preserve their social status, though in different ways. Consistent with the finding that customers of low and high system confidence prefer different brands that signal 
support for their social system (Shepherd et al., 2015), this paper suggests that upperclass individuals experience a stronger promotion focus-mentoring relationship fit, which helps them preserve social status by gaining competence (Weiss and Morrison, 2019). In contrast, lower-class individuals experience a stronger prevention focuspartnering relationship fit, which helps them preserve social status by avoiding losses and negative outcomes and emphasizing equality (Kraus et al., 2012; Shepherd et al., 2015).

\section{Managerial implications}

As demonstrated in prior research, customer participation is not always beneficial to service firms and customers (Chan et al., 2010; Dong et al., 2015). This paper suggests that managing service relationships in service co-production can be an effective way to benefit from service co-production. The practical value of the regulatory fit effects in service co-production is manifested in two aspects. On the one hand, service firms should be aware of or even temporarily manipulate the service relationship to boost the effectiveness of service appeals. If service appeals emphasize promotion (versus prevention)-focused benefits, developing a mentoring (versus partnering) relationship with customers in service co-production is more effective in enhancing customers' purchase intention.

On the other hand, service firms should also be aware of customers' social class. Suppose service firms adopt promotion-focused (prevention-focused) service appeals and act as a mentor (partner) of customers in service co-production. In that case, they should better target high (low) social class customers or utilize customers' high (low) 
subjective social status. For example, service firms could use membership to manipulate customers' perceived social class. They can use prevention-focused appeals and act as a partner in service co-production for customers with low-rank membership. For customers of premium membership, promotion-focused appeals with the mentoring relationship will be more effective.

\section{Limitations and future research}

This research has several limitations. The research only adopts scenario-based experiments in various service settings to test hypotheses. Although we manipulated the independent variables in more practical ways and recruited real customers online, the scenario-based designs hinder our findings from generalizing to real service settings. Future research could test the regulatory fit effects by employing field study designs in diverse service settings such as online course learning and financial banking services contexts where customers and service firms do not interact face-toface or interact with Artificial Intelligence instead of humans. Consequently, the quality and strength of service relationships in face-to-face condition and virtual condition could differ and further moderate the regulatory fit effect.

Secondly, the empirical studies only used purchase intention as the dependent variable. Future research could measure other important attitudinal service outcomes, such as customer loyalty, service satisfaction, and word of mouth. Behavioral variables could also be considered in future research, such as the amount of money customers allocate to purchase a specific service and the frequency that customers engage in the service purchased. 
Third, this paper only uses social class as a moderator to demonstrate the boundary and the underlying psychological process of the regulatory fit effects in services. Future research could explore other moderators such as power (Sassenberg et al., 2007), individuals' chronic regulatory focus (Werth and Foerster, 2007), and independence and interdependence self-view (Aaker and Lee, 2001). Further research could also explore the cognitive process of the regulatory fit effects demonstrated in a prior study (Zhu \& Meyers-Levy, 2007). 


\section{References}

Aaker, J. L. and Lee, A. Y., (2001), "'I" seek pleasures and "we" avoid pains: The role of selfregulatory goals in information processing and persuasion", Journal of Consumer Research, Vol. 28 No. 1, pp.33-49.

Aggarwal, P. and McGill, A. L., (2012), "When brands seem human, do humans act like brands? Automatic behavioral priming effects of brand anthropomorphism", Journal of Consumer Research, Vol. 39 No. 2, pp.307-323.

Alhouti, S., Wright, S. A. and Baker, T. L., (2019), "Responding to service failures with prevention framed donations", Journal of Services Marketing, Vol. 33 No. 5, pp.547-556.

Allen, T. D., Eby, L. T., Chao, G. T. and Bauer, T. N., (2017), "Taking stock of two relational aspects of organizational life: Tracing the history and shaping the future of socialization and mentoring research", Journal of Applied Psychology, Vol. 102 No. 3, pp.324-337.

Amaral, N. B. and Loken, B., (2016), "Viewing usage of counterfeit luxury goods: Social identity and social hierarchy effects on dilution and enhancement of genuine luxury brands", Journal of Consumer Psychology, Vol. 26 No. 4, pp.483-495.

Anderson, C. and Kilduff, G. J., (2009), "The pursuit of status in social groups", Current Directions in Psychological Science, Vol. 18 No. 5, pp.295-298.

Avnet, T. and Higgins, E. T., (2006), "Response to comments on "how regulatory fit affects value in consumer choices and opinions"'", Journal of Marketing Research, Vol. 43 No. 1, pp.2427.

Bakker, A. B., Tims, M. and Derks, D., (2012), "Proactive personality and job performance: The 
role of job crafting and work engagement", Human Relations, Vol. 65 No. 10, pp.13591378.

Briley, D. A. and Wyer, R. S., (2002), "The effect of group membership salience on the avoidance of negative outcomes: Implications for social and consumer decisions", Journal of Consumer Research, Vol. 29 No. 3, pp.400-415.

Buettgen, M., Schumann, J. H. and Ates, Z., (2012), "Service locus of control and customer coproduction: The role of prior service experience and organizational socialization", Journal of Service Research, Vol. 15 No. 2, pp.166-181.

Cesario, J., Grant, H. and Higgins, E. T., (2004), "Regulatory fit and persuasion: Transfer from "feeling right"", Journal of Personality and Social Psychology, Vol. 86 No. 3, pp.388-404.

Chan, K. W., Yim, C. K. and Lam, S. S. K., (2010), "Is customer participation in value creation a double-edged sword? Evidence from professional financial services across cultures", Journal of Marketing, Vol. 74 No. 3, pp.48-64.

Chen, C., Wen, P. and $\mathrm{Hu}, \mathrm{C} .$, (2017), "Role of formal mentoring in protégés' work-to-family conflict: A double-edged sword", Journal of Vocational Behavior, Vol. 100 No. jun., pp.101-110.

Chen, E. and Matthews, K. A., (2001), "Cognitive appraisal biases: An approach to understanding the relation between socioeconomic status and cardiovascular reactivity in children", Annals of Behavioral Medicine, Vol. 23 No. 2, pp.101-111.

Dong, B., Sivakumar, K., Evans, K. R. and Zou, S., (2015), "Effect of customer participation on service outcomes: The moderating role of participation readiness", Journal of Service Research, Vol. 18 No. 2, pp.160-176. 
Dong, B., Sivakumar, K., Evans, K. R. and Zou, S., (2016), "Recovering coproduced service failures: Antecedents, consequences, and moderators of locus of recovery", Journal of Service Research, Vol. 19 No. 3, pp.291-306.

Gutek, B. A., Bhappu, A. D., Liao-Troth, M. A. and Cherry, B., (1999), "Distinguishing between service relationships and encounters", Journal of Applied Psychology, Vol. 84 No. 2, pp.218-233.

Haggard, D. L., Dougherty, T. W., Turban, D. B. and Wilbanks, J. E., (2011), "Who is a mentor? A review of evolving definitions and implications for research", Journal of Management, Vol. 37 No. 1 , pp.280-304.

Huang, X. I., Li, X. and Zhang, M., (2013), "'Seeing" the social roles of brands: How physical positioning influences brand evaluation", Journal of Consumer Psychology, Vol. 23 No. 4, pp.509-514.

Kim, H. C. and Kramer, T., (2015), "Do materialists prefer the "brand-as-servant"? The interactive effect of anthropomorphized brand roles and materialism on consumer responses", Journal of Consumer Research, Vol. 42 No. 2, pp.284-299.

Kraus, M. W., Horberg, E. J., Goetz, J. L. and Keltner, D., (2011), "Social class rank, threat vigilance, and hostile reactivity", Personality and Social Psychology Bulletin, Vol. 37 No. 10, pp.1376-1388.

Kraus, M. W., Piff, P. K., Mendoza-Denton, R., Rheinschmidt, M. L. and Keltner, D., (2012), "Social class, solipsism, and contextualism: How the rich are different from the poor", Psychological Review, Vol. 119 No. 3, pp.546-572.

Kwan, H. K., Mao, Y. and Zhang, H., (2010), "The impact of role modeling on proteges' personal 
learning and work-to-family enrichment", Journal of Vocational Behavior, Vol. 77 No. 2, pp.313-322.

Lee, A. Y. and Aaker, J. L., (2004), "Bringing the frame into focus: The influence of regulatory fit on processing fluency and persuasion", Journal of Personality and Social Psychology, Vol. 86 No. 2, pp.205-218.

Lee, A. Y., Aaker, J. L. and Gardner, W. L., (2000), "The pleasures and pains of distinct selfconstruals: The role of interdependence in regulatory focus", Journal of Personality and Social Psychology, Vol. 78 No. 6, pp.1122-1134.

Lee, A. Y., Keller, P. A. and Sternthal, B., (2010), "Value from regulatory construal fit: The persuasive impact of fit between consumer goals and message concreteness", Journal of Consumer Research, Vol. 36 No. 5, pp.735-747.

Magee, J. C. and Galinsky, A. D., (2008), "Social hierarchy: The self-reinforcing nature of power and status", Academy of Management Annals, Vol. 2 No., pp.351-398.

Malaviya, P. and Sternthal, B., (2009), "Parity product features can enhance or dilute brand evaluation: The influence of goal orientation and presentation format", Journal of Consumer Research, Vol. 36 No. 1, pp.112-121.

Medler-Liraz, H., (2016), "The role of service relationships in employees' and customers' emotional behavior, and customer-related outcomes", Journal of Services Marketing, Vol. 30 No. 4, pp.437-448.

Mende, M. and van Doorn, J., (2015), "Coproduction of transformative services as a pathway to improved consumer well-being: Findings from a longitudinal study on financial counseling", Journal of Service Research, Vol. 18 No. 3, pp.351-368. 
Pham, M. T. and Chang, H. H., (2010), "Regulatory focus, regulatory fit, and the search and consideration of choice alternatives", Journal of Consumer Research, Vol. 37 No. 4, pp.626-640.

Piff, P. K., Kraus, M. W., Cote, S., Cheng, B. H. and Keltner, D., (2010), "Having less, giving more: The influence of social class on prosocial behavior", Journal of Personality and Social Psychology, Vol. 99 No. 5, pp.771-784.

Poushneh, A. and Vasquez-Parraga, A. Z., (2017), "Discernible impact of augmented reality on retail customer's experience, satisfaction and willingness to buy", Journal of Retailing and Consumer Services, Vol. 34 No., pp.229-234.

Sassenberg, K., Jonas, K. J., Shah, J. Y. and Brazy, P. C., (2007), "Why some groups just feel better: The regulatory fit of group power", Journal of Personality and Social Psychology, Vol. 92 No. 2, pp.249-267.

Shepherd, S., Chartrand, T. L. and Fitzsimons, G. J., (2015), "When brands reflect our ideal world: The values and brand preferences of consumers who support versus reject society's dominant ideology", Journal of Consumer Research, Vol. 42 No. 1, pp.76-92.

Snoeren, M. M. W. C., Raaijmakers, R., Niessen, T. J. H. and Abma, T. A., (2016), "Mentoring with(in) care: A co-constructed auto-ethnography of mutual learning", Journal of Organizational Behavior, Vol. 37 No. 1, pp.3-22.

Tonidandel, S., Avery, D. R. and Phillips, M. G., (2007), "Maximizing returns on mentoring: Factors affecting subsequent protege performance", Journal of Organizational Behavior, Vol. 28 No. 1, pp.89-110.

Weiss, M. and Morrison, E. W., (2019), "Speaking up and moving up: How voice can enhance 
employees' social status", Journal of Organizational Behavior, Vol. 40 No. 1, pp.5-19.

Werth, L. and Foerster, J., (2007), "How regulatory focus influences consumer behavior", European Journal of Social Psychology, Vol. 37 No. 1, pp.33-51.

Wu, X., Lyu, Y., Kwan, H. K. and Zhai, H., (2019), "The impact of mentoring quality on proteges' organization-based self-esteem and proactive behavior: The moderating role of traditionality", Human Resource Management, Vol. 58 No. 4, pp.417-430.

Zhou, A. J., Lapointe, E. and Zhou, S. S., (2019), "Understanding mentoring relationships in china: Towards a confucian model", Asia Pacific Journal of Management, Vol. 36 No. 2, pp.415444.

Zhu, R., \& Meyers-Levy, J. (2007). Exploring the cognitive mechanism that underlies regulatory focus effects. Journal of Consumer Research, Vol. 34 No. 1, pp. 89-96. 


\section{Figure 1. Conceptual model}

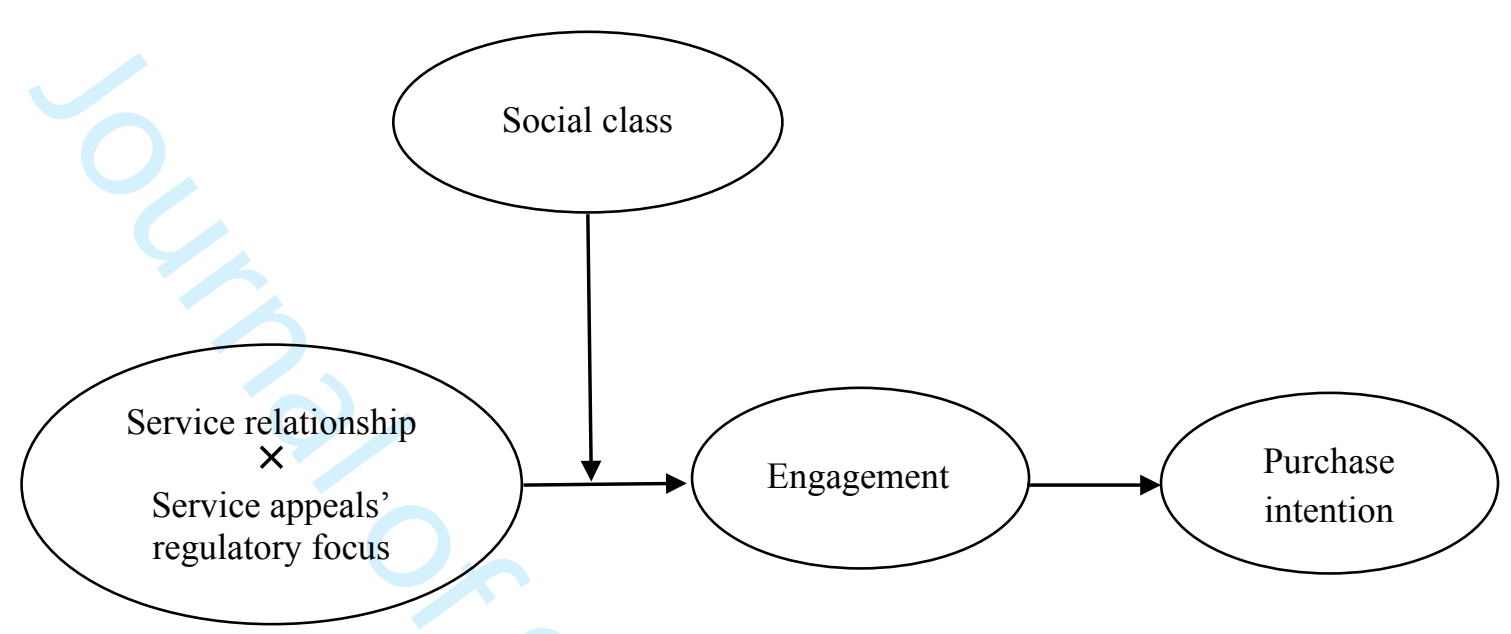


Figure 2. Purchase intention as a function of service appeals' regulatory focus and service relationship (Experiment 1)

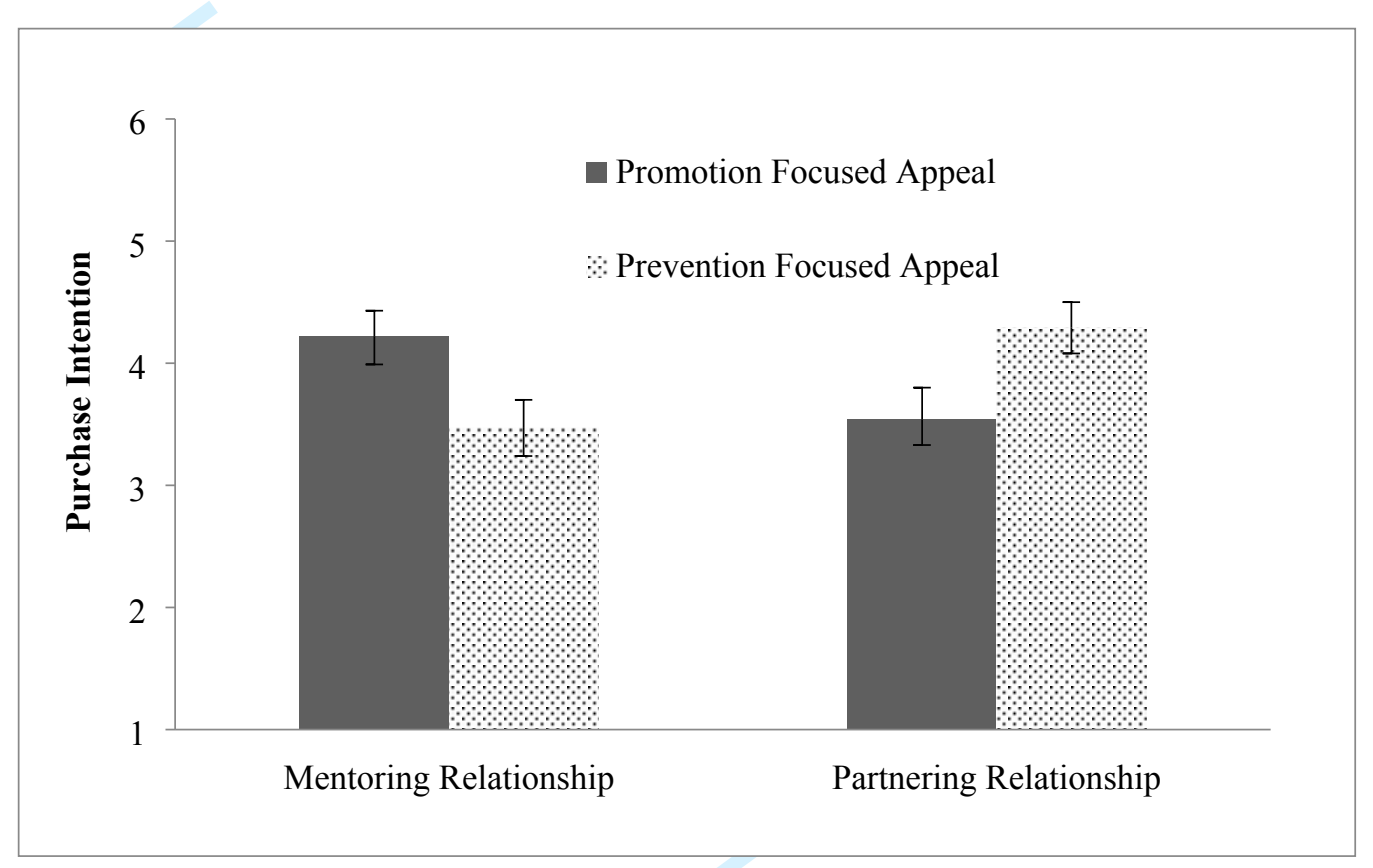


Figure 3. Purchase intention as a function of service appeals' regulatory focus and service relationship (Experiment 2)

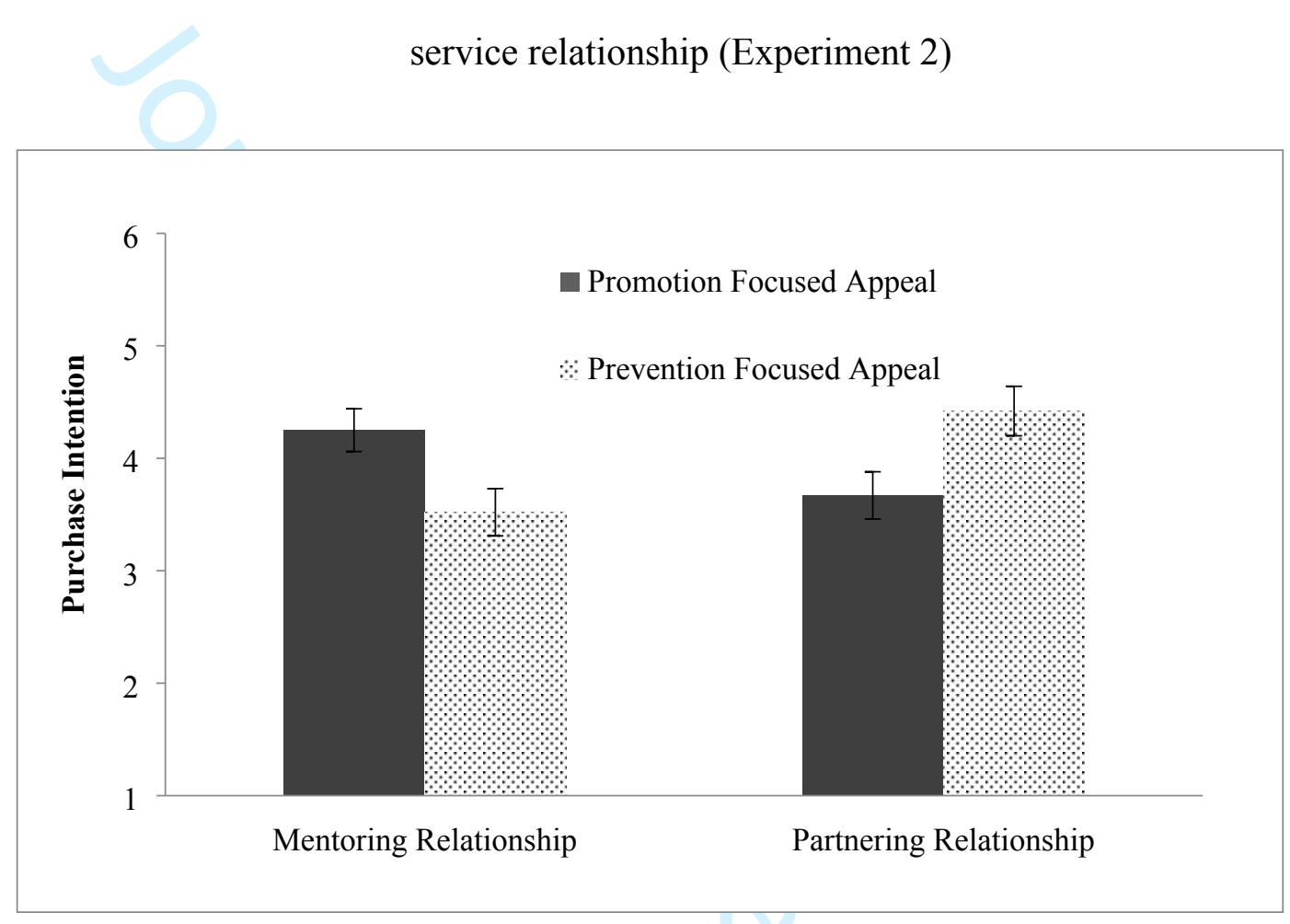


Table 1. Regression results (Experiment 2)

\begin{tabular}{|c|c|c|c|c|}
\hline & Model 1 & Model 2 & Model 3 & Model 4 \\
\hline Predictors & $\beta$ & $\beta$ & $\beta$ & $\beta$ \\
\hline \multicolumn{5}{|l|}{ Control variables } \\
\hline Gender & $-.53 *$ & $-.52 *$ & -.41 & $-.41 *$ \\
\hline Age & .11 & .11 & .09 & .06 \\
\hline Income & .00 & .00 & .00 & .00 \\
\hline Previous experience & -.07 & -.07 & -.05 & -.05 \\
\hline \multicolumn{5}{|l|}{ Independent variables } \\
\hline Service appeals' regulatory-focus & & .00 & .00 & -.01 \\
\hline Service relationship & & -.01 & .01 & .02 \\
\hline \multicolumn{5}{|l|}{ Interaction } \\
\hline Interaction effect & & & $.30^{* *}$ & .18 \\
\hline \multicolumn{5}{|l|}{ Mediator } \\
\hline Engagement & & & & $.45^{* * *}$ \\
\hline \multicolumn{5}{|l|}{ Model summary } \\
\hline$R^{2}$ & .085 & .085 & .137 & .301 \\
\hline Adjusted $R^{2}$ & $.055^{*}$ & .040 & $.087 * *$ & $.254^{* * *}$ \\
\hline
\end{tabular}

*significant at $p<.05 ; * *$ significant at $p<.01 ; * * *$ significant at $p<.001$ 
Figure 4. The mediating effect of engagement on the relationship between regulatory fit and purchase intention (Experiment 2)

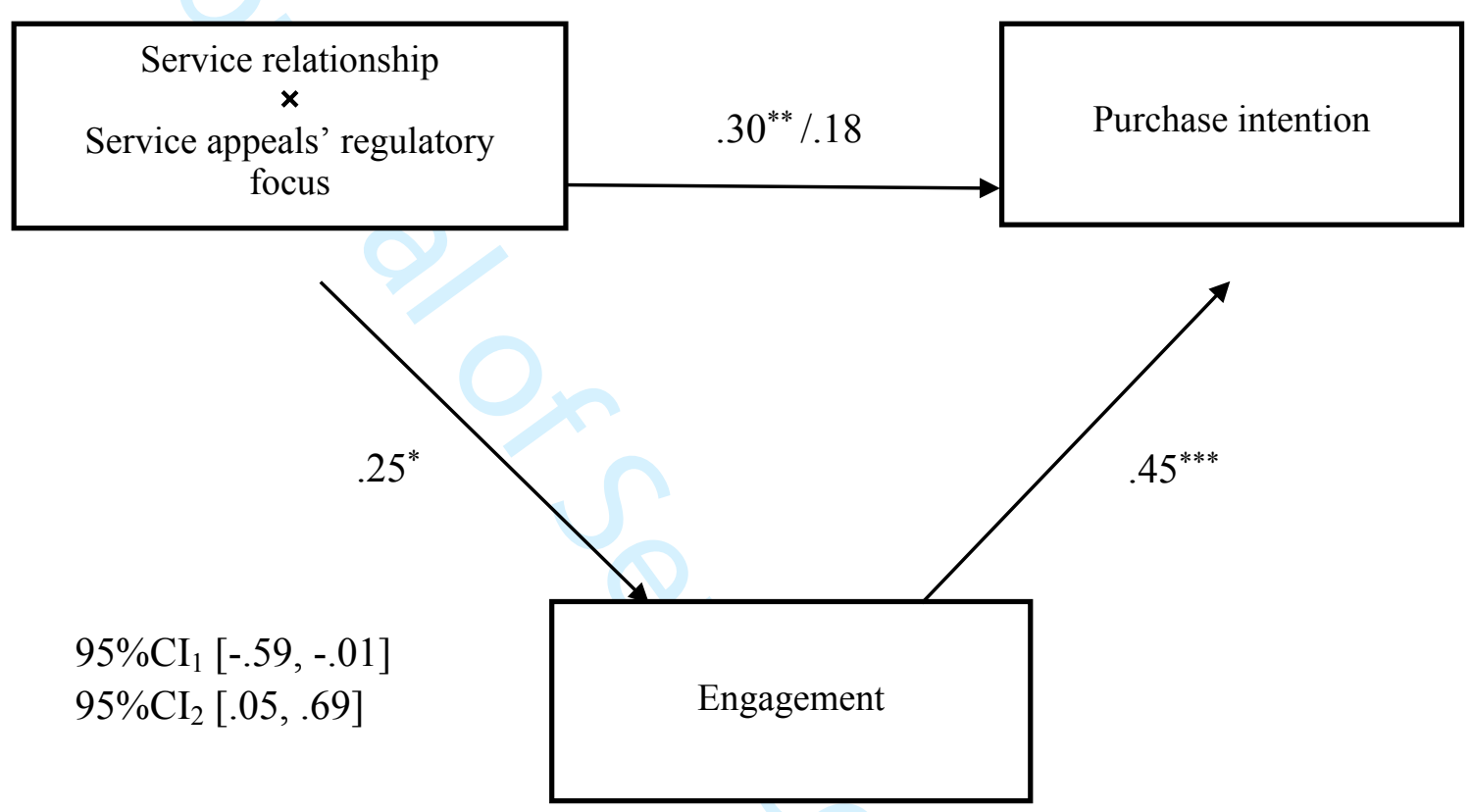

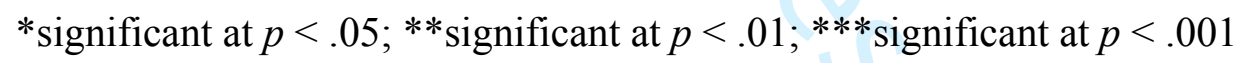


Figure 5. Purchase intention as a function of service appeals' regulatory focus and

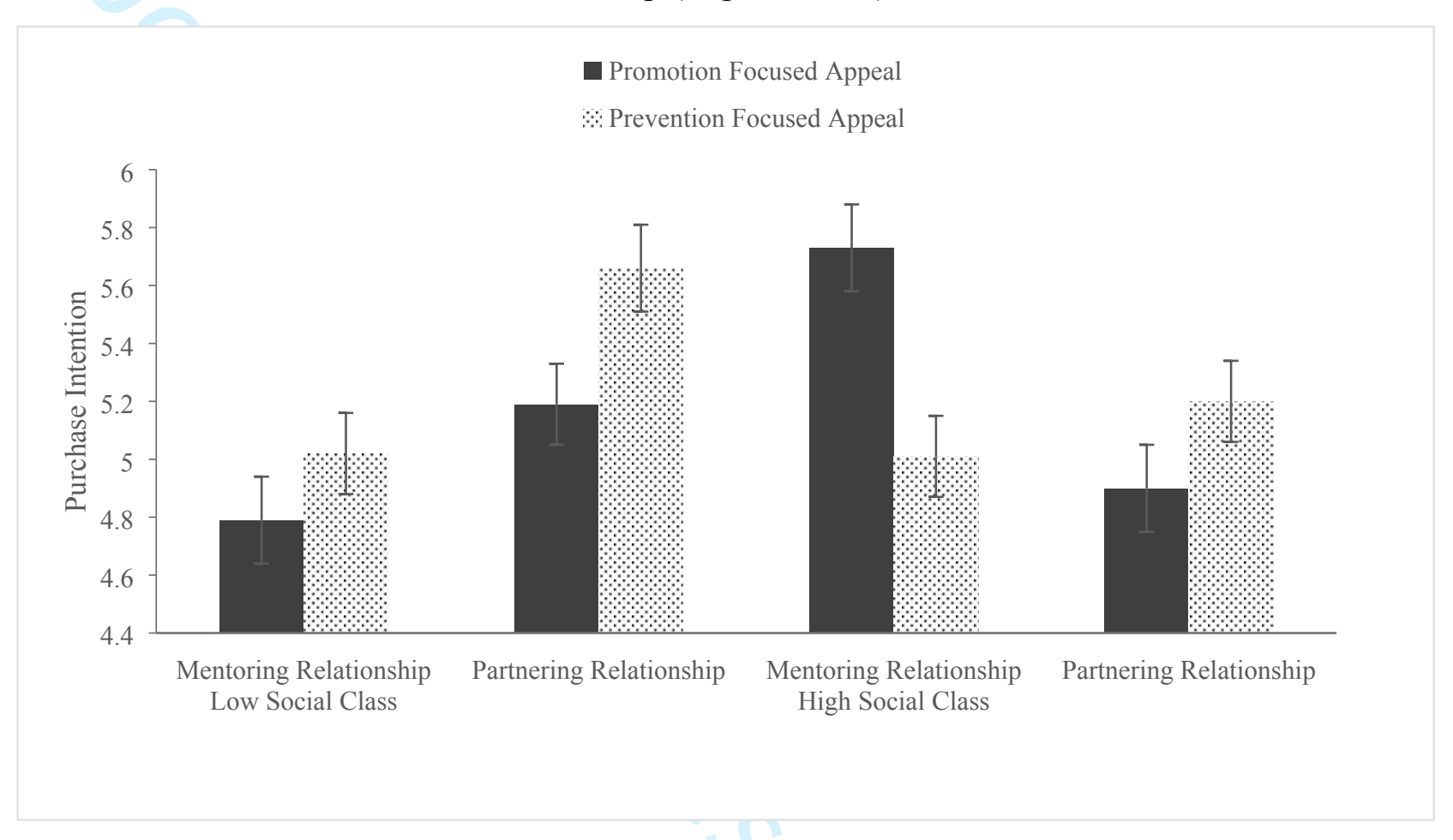

